\title{
EFFECT OF STRATEGIC ALLIANCE AND PARTNERSHIP ON THE SURVIVAL OF MSMES POST COVID-19 PANDEMIC
}

\author{
Abideen A. Tijani ${ }^{1, a}$, Reuben O. Osagie ${ }^{2, b,{ }^{*}}$ and Kayode B. Afolabi ${ }^{3, c}$ \\ ${ }^{1}$ Lecturer, Business Administration Department, Faculty of Management Sciences, Lagos \\ State University, Lagos, Nigeria \\ ${ }^{2}$ Doctoral Student, Business Administration Department, Faculty of Management Sciences, \\ Lagos State University, Lagos, Nigeria \\ ${ }^{3}$ Doctoral Student, Business Administration Department, Faculty of Management Sciences, \\ Lagos State University, Lagos, Nigeria \\ aabadeen080@yahoo.com, ${ }^{b}$ reubenosagie@gmail.com, ${ }^{\mathrm{c}}$ babsafo@gmail.com \\ *Corresponding author
}

Cite as: Tijani, A.A., Osagie, R.O., Afolabi, B.K. (2021). Effect of strategic alliance and partnership on the survival of MSMEs post COVID-19 pandemic, Ekonomicko-manazerske spektrum, 15(2), 126-137.

Available at: dx.doi.org/10.26552/ems.2021.2.126-137

Received: 15 July 2021; Received in revised form: 24 September 2021; Accepted: 10 October 2021; Available online: 30 December 2021

\begin{abstract}
:
Research background: This study was conducted as a result of the challenges that confront MSMEs globally, especially in Nigeria, due to the lockdown occasioned by COVID-19. A descriptive research design (quantitative analysis) was adopted, while primary data were employed for the study.

Purpose of the article: The population for the study was 587 MSMEs from the Ojo local government area of Lagos State, Nigeria, with a sample size of 234 derived using the Taro Yamane (1967) techniques. A total of 240 questionnaires were distributed, allowing room for errors, and 228 of them were returned usable for the study, constituting a $95 \%$ response rate for the study.

Methods: Content validity was adopted. A reliability test was conducted using Cronbach's Alpha, which returned a value of 0.869 , indicating internal consistency of the research instrument. Descriptive statistics (means and simple percentages) were used to analyse the data, alongside regression and Pearson's correlation coefficients. The findings revealed that a strategic alliance and partnership could positively affect MSMES survival post-COVID-19 in Nigeria, with a p-value of $0.000<0.05$, and that its impact on the performance of MSMEs in the Nigerian economy post-Covid-19 was statistically significant and positive, with a correlation coefficient of $0.824(82.4 \%)$ and a p-value of $0.000<0.05$.

Findings \& Value added: The results and findings suggest that a strategic alliance and partnership is indeed a veritable tool for MSMEs' survival post-COVID-19 in Nigeria.
\end{abstract}

Keywords: COVID-19 pandemic, MSMES survival, strategic alliance and partnership, veritable tool

JEL Classification: L1, L14, L24, L25, M1, M10, M2, M21 


\section{Introduction}

A strategic alliance entails a situation in which two or more companies align to share resources and activities to pursue a common strategic objective. This decision may be due to several reasons, including a high cost of capital associated with resources required, environmental factors, legal requirements, and the technical know-how required by the resources. In Nigeria, strategic alliances have become popular as a means of surviving the evermultifarious environment. Their use extends across sectors of the Nigerian economy such as the banking, oil, manufacturing, and even the service sectors (Ekpudu et al., 2012).

Strategic alliances have existed in Nigeria since the early 1980s (Ekpudu et al., 2012). This strategy as a means of business survival has become more obvious in recent years due to the effects or pressure of the globalisation of local firms, unfavourable rivalries among firms, the global economic meltdown, minimum capital requirements as demanded by regulatory authorities, and lately, the effect of the global coronavirus (COVID-19) pandemic. COVID-19 and its leverage on the close-knit world due to globalisation have affected the global economy, not sparing even mighty industrialised nations such as China, the USA, the United Kingdom, Germany, France, Switzerland, Russia, and Canada (Sipahi, 2020). Developing and third-world nations are the most adversely affected economically, and the Nigerian economy is indeed suffering from the effects of the aftermath of COVID-19 in all the sectors. The small and medium enterprises (SMEs), which are supposed to be the catalysts and agents of economic development in these developing countries, have not been spared, while the entrepreneurs have virtually expended their business capital on family and staff welfare due to the three (3) months of lockdown occasioned by the COVID-19 pandemic (WHO, 2020).

According to Oke and Aluko (2015) and Musah (2017), organisations can, through strategicalliance competitive positioning, gain entry to new markets, supplement critical skills, and share risks or costs associated with environmental challenges and major development projects. A strategic alliance, by definition, is a business partnership that exists where there is a combination of effort and resources to accomplish objectives that will result in desired rewards for each of the entities involved in the long run. The basic idea behind a strategic alliance is to minimise risk while maximising the utilisation of financial, technical, physical, and management resources, with a clearly defined purpose and exit strategy.

Organisations globally, and indeed Nigeria, are either folding up, liquidated, or operating below their normal capacities due to the COVID-19 pandemic and the ensuing challenges that affect the economic and business environments. These challenges include raising adequate capital to continue operations, lack of finance for needed materials, high cost of procuring needed materials for operations, and inadequate access to loans and credit facilities. According to Mohammad et al. (2020), COVID-19 has affected all sectors: e-commerce, technology, business, travel, etc., in every economy of the world. Private and public sectors have been devastated by the effect of this virus, which has hampered the macro economy as a whole. Businesses' supply chains have been disrupted; the production and manufacturing sectors have also been severely affected; import and export facilities have been obstructed globally; online businesses face shortages of products which are needed by customers. In Nigeria, the impact of COVID-19 and its occasioned lockdown on businesses cannot be quantified; organisations and business owners are complaining about continuous operations, the payment of workers' salaries (with no opportunity to furlough), the unavailability of raw materials, and having to survive with no support from government in sight. These and many more issues affect multinational corporations, international business organisations, and large-scale corporations. SMEs are the most adversely affected by the impact of the pandemic on national economies. El-Erian (2020) argued that the unexpected disruption of economic activities occasioned by Covid-19 was not 
merely destructive, but had a spill over effect by creating demand and supply shocks in almost every area of human endeavour.

Ozili and Arun (2020) obtained data from IATA which showed that the effect of COVID-19 on the aviation industry was a total loss of $\$ 113$ billion; the tourism industry was estimated to have lost of over $\$ 200$ billion globally, excluding other loss of revenue from tourism travel, while the business travel sector was estimated to have lost $\$ 820$ billion in revenue, according to the GTBA. Many hotels worldwide announced temporary suspensions of normal operations, which put the estimated job losses at 24.3 million globally. The sports industry was severely affected during the coronavirus outbreak; the resulting loss in revenue to the sponsors and organisers of cancelled games ran into billions of dollars. The effect of the pandemic on oildependent countries was severe (WHO, 2020). There was a global drop in oil prices which, combined with low demand for oil products in the international market, led to a significant deficit in oil revenue to oil-dependent countries; in turn, this led to an increase in current account deficits and worsened the balance-of-payment positions of many oil-dependent countries such as Nigeria. Consequently, there were massive deficits in the national budgets of most oildependent countries, which forced them to either seek foreign loans from the IMF, the World Bank, and other lenders, or to create new budgets that were priced based on the prevailing low oil price in the global market (Ozili and Arun, 2020).

According to Ozili and Arun (2020), private sector banks were exposed to the highest credit risk during the pandemic; non-performing loans rose sharply as a result of loans issued to SMEs, airlines, hotels, tour operators, restaurants, retail, construction, and real estate businesses. During the pandemic, a general drop arose in the volume of bank transactions and card payments, while there was a reduction in the use of ATM cash machines worldwide. The most noticeable outcome of the COVID-19 crisis in financial markets was its effect on the global stock market. Global stock markets lost $\$ 6$ trillion in value over six days, from 23 to 28 February, according to the S\&P and Dow Jones indices. In the education sector, UNESCO reported that the COVID-19 outbreak affected the education of at least 290.5 million students worldwide. Public schools were closed in the USA, some schools were shut in Australia, while most other countries, such as Israel, Nigeria, Egypt, Italy, France, and Spain, shut down all schools, which created some form of unemployment for teachers. Examinations in all colleges and universities in Northern Ireland were suspended by her government. The entertainment, event, and other major service sectors were not left out, with cancellations of major events resulting in losses amounting to trillions of dollars.

Most organisations, from multinational corporations, large-scale organisations, and international enterprises to micro, small, and medium enterprises (MSMEs) across all sectors of business are beginning to fold up: some are laying off staff as a cost-cutting measure, while those in developed countries, such as the USA, the UK, Germany, Russia, Canada, and China, are furloughing staff to their respective country governments; those in countries that cannot enjoy such benefits have had to device means of staying afloat while designing work schedules that require less overhead payments (BBC report July, 2020; Sipahi, 2020). The cost of importation of raw materials has risen steeply; most organisations are looking for local sources that are even hard to come by and very expensive, given that the local raw materials are limited in supply and as such are available to the highest bidder (Ozili and Arun, 2020).

Over time, a strategic alliance has been seen by researchers and business owners as a tool for expanding an existing business, exploiting new markets, improving product lines, or developing and sustaining competitive advantage, but not as a tool for business survival, least of all MSMEs, and this is the rationale behind this study. 
Objectives of the Study - The objective of this study, titled, 'Strategic Alliance and Partnership: Veritable Tools for MSMEs Survival post-COVID-19 Pandemic', is to ascertain the following:

1. To examine the effect of strategic alliance and partnership on MSMEs' survival postCOVID-19.

2. To evaluate the impact of strategic alliance and partnership on the performance of MSMEs in the Nigerian economy post-COVID-19.

Research Hypotheses

$\mathrm{H}_{1}$ : Strategic Alliance and Partnership does not have an effect on MSMEs' survival postCOVID-19.

$\mathrm{H}_{2}$ : Strategic Alliance and Partnership does not have any positive impact on the performance of MSMEs in the Nigerian economy post-COVID-19.

\section{Literature Review}

Strategic Alliance and Partnership: A strategic alliance is an agreement between two companies to embark on a mutually advantageous project while each retains its individuality. The agreement is less intricate and less obligatory than a joint venture, in which two businesses pool resources to produce a distinct business entity. A company may enter a strategic alliance to expand its product line, enter into a new market, or attain competitive advantage. The arrangement allows two businesses to work towards a mutually beneficial goal. The relationship may be short-term or long-term, and it may be formal or informal. While a strategic alliance can be an informal alliance, the responsibilities of each member are clearly defined. The needs and benefits gained by the partnered businesses will dictate how long the coalition is in effect (Ekpudu et al., 2012).

- A strategic alliance is an agreement between two companies that wish to share resources to undertake a specific, conjointly beneficial project.

- A strategic alliance arrangement could help a company develop a more effective process.

- Strategic alliances allow two organisations, individuals, or other entities to work towards mutual or associated goals.

Developing a strategic alliance can allow each of the businesses to attain gradual growth more quickly than if they had acted alone. The partnership often involves sharing resources that only one of the businesses possesses. Strategic alliances can be elastic because the two businesses do not need to combine capital and can remain independent of each other. A Strategic alliance, however, has its own risks. While the arrangement is usually perfect for both companies, there may be differences in how the firms conduct their businesses, which may create conflict. Furthermore, if the alliance necessitates the parties to share copyrighted information, it must come with trust between the two allies. In a long-term strategic alliance, one party may become reliant on the other, and the disruption of such an alliance can be detrimental to the companies involved.

Processes of Strategic Alliance and Partnership: According to Mohamed (2014), before entering into a strategic alliance and partnership, there are certain fundamental factors that must be observed: selection of appropriate partners for the projected objectives; sharing of appropriate information; discussion of a deal that includes risk and benefit; agreement on an achievable arrangement on time; agreement on a common, flexible commitment on what is suitable for changing, measuring, and sharing within each partner's culture; and respecting and protecting each partner's brand. For a strategic alliance and partnership to be successful, a 
Effect of strategic alliance and partnership on the survival of MSMEs post COVID-19 pandemic Authors: Abideen A. Tijani, Reuben O. Osagie,

Kaynode B. Afolabi

process of setting an alliance strategy must be followed; in setting the alliance strategy, the organisations, businesses, enterprises, and management must properly identify the motive for entering the alliance.

Types of strategic alliances according to Mohamed (2014):

- Joint Venture: This is an arrangement by two parties or more to form a single entity aimed at undertaking a certain project; the parties have equal stakes in the business, and share revenues, expenses, and profits.

- Global Strategic Alliances: This is a working partnership, usually between two or more organisations across national borders and, increasingly, across industries. This alliance is occasionally arranged between organisations and a foreign government, or among organisations and governments.

- Equity Strategic Alliance: This is an alliance in which two or more firms own varying percentages of the formed company by conjoining some of their resources and competencies to create a competitive advantage.

- Non-Equity Strategic Alliance: This is an alliance in which two or more firms enter into a contractual relationship to share some of their unique resources and capabilities to create a competitive advantage.

MSMEs: The National Policy on Micro, Small, and Medium Enterprises (MSMEs) in Vision 2020 defines MSMEs in Nigeria as being subjugated by wholesale and retail trade, manufacturing and vehicle repair/servicing, transport, hotels and restaurants, and building and construction (Adelekan et al., 2019; Aminu and Shiraff, 2017; Ribeiro-Soriano, 2017). Most mainstream MSMEs are informal, family-owned businesses with low output worth and low levels of skills and technology. MSMEs are widespread nationally due to the simple admittance requirements. Targeted interventions in the form of funding, technology upgrade, and training will contribute significantly to increasing the very low number of micro-enterprises transitioning into SMEs (Ayandibu and Houghton, 2017; Eze and Cesar, 2021; Eze et al., 2019). This will result in the multiplier effects of employment generation and the reduction of poverty incidence. Most SMEs in Nigeria are family-owned, have low capital bases, are located in urban and semi-urban areas, and largely reside in the informal sector. The informal sector in Nigeria refers to the economic activities in all the sectors of the economy that are operated outside the purview of government regulation (Ifekwem and Adedamola, 2016).

Transaction Cost Theory: Williamson (1979), as cited in Bremen et al. (2010), defined transaction cost as an alternative method of organising transactions in the form of structures related to markets, hybrids, firms, and bureaus that minimise transaction costs. Transaction cost theory, according to Williamson's postulation in 1986 and 1999, as cited in Bremen et al. (2010), is the ideal organisational structure that aims to achieve economic competence by minimising the costs of organisational exchange. The theory suggests that each type of transaction produces the coordination costs of monitoring, controlling, and managing transactions. Williamson defined transaction costs broadly as the costs of running an economic system of firms. He argued that such costs were to be distinguished from production costs, and that a decision-maker could make a choice to use a firm structure or source from the market by comparing transaction costs with internal production costs. Thus, cost is the primary determinant of such a decision. Transaction cost theorists argue that firms agree to equity agreements to economise on transaction costs when there is a non-negligible risk of opportunism, but not so much as to mandate hierarchical internalisation (Colombo, 2003). The equity form of transaction costs is more suitable for complex alliances (those that link together several partners and/or have broad product, technology, or activity scope) and for alliances that 
have a technological component. Imperfect information and the fact that partners may behave opportunistically result in a situation in which parties are forced to make decisions oblivious to the actions of other market players, which creates what is known as behavioural uncertainty, since the possible consequences of such performance occur as a result of subjective rather than rational human behaviour (Nooteboom, 2004; Khanna et al., 2000; Anand and Khanna, 2000). Bremen et al. (2010) refers to external uncertainty, which embraces the probability of encountering unexpected changes in the legal and economic environments.

The importance of transaction cost theory to this research is the need to maintain and minimise organisational exchange cost in the face of the behavioural uncertainty created by the COVID-19 pandemic; it must be noted that organisations must consider operational cost as more important in this uncertain period.

Strategic Alliance as a Veritable Tool for the Survival of MSMEs post-COVID-19 'Empirical Review': The table below shows some notable empirical findings on strategic alliance and SMEs/business performance. It must be noted that not all alliances are successful (Arndt, 2009; below).

Table 1: Empirical Findings on Strategic Alliance and SME Performance

\begin{tabular}{ccc}
\hline Year & Author(s) & Title \\
\hline & & \\
& & \\
& & Impact of Coronavirus (COVID- \\
& Mohammad et al., & 19) on E-Business in Malaysia
\end{tabular}

Findings

That the country's economic growth has lowered down, there has been a shaken up all types of business including the e-commerce business on a massive scale, major retailers have temporarily shuttered their stores, the medium and small-sized retailers are also affected. They concluded that COVID-19 has severely impacted the Malaysian online business especially the Chinese products.

The results revealed that production has significant effect on sales revenue while marketing alliances has effect on sales revenue. It also showed a positive effect of technology alliance on firms' effectiveness. In the light of the findings,

Strategic Alliance and Firm Performance: A Focus on Service Industry

Effectiveness of Horizontal Strategic Alliances in Technologically Uncertain Environments, are Trust and Commitment Enough?

Competitive Strategies, Strategic Alliances, and Performance in International High Tech the study submitted that strategic alliance is indeed a veritable tool in enhancing organizational performance. The study recommended that management of the organization should adopt strategic alliance as a way of restructuring their organizations and improve general performance.

The result revealed a positive significant relationship between participation in strategic alliances and business performance.

He concluded that using strategic alliances improves performance regardless of the type of competitive 
Technical Strategic Alliances and Performances: The Mediating Effect of Knowledge-Based Competencies.

Enhancing Organizational Performance through Strategic Technology Alliances: A Study on Malaysian Manufacturers.

Strategic Alliances International Marketing.

Cisco's Failure in Corporate Alliances. strategy used, the country of origin, or the industry in which the alliances are established.

They conducted a study on the effect of participation in technological strategic alliances on business performance by considering the knowledge-based distinctive competencies as a mediating variable using a sample of Spanish firms. Results from their findings prove that the relationship between research and development (R\&D), innovation strategic alliances, and performance is mediated by the generation of knowledge-based distinctive competencies; and that the contribution of the participation in alliances to the growth of the firm's knowledge stock depends on its creation of innovation competencies.

The result indicated that collaborations and partnerships is factor of consideration to enhance capabilities and performance. This means that firms planning to improve their performance need to consider alliances with other firms especially those in manufacturing sector. More companies today are partnering with other members of the supply chain as alliances to improve the performance of the customer value-delivery network.

He identified a successful Strategic alliance in Starbucks and Kraft where Starbucks coffee was to be distributed through Kraft only. In the end both companies benefited. Starbucks gained quick entry into 25,000 supermarkets in the USA, supported by the marketing muscle of 3,500 Kraft salespeople and Kraft topped off its coffee line with the best-known premium brand and gained quick entry into the fast-growing premium coffee segment. This alliance clearly leads to market penetration, brand recognition and profitability for both partners hence the development of competitive advantage.

He observed that Cisco had had two failed alliances with Motorola and Ericsson. The partners had turned into competitors because of acquisitions. Acquisitions had turned allies into adversaries. With insider knowledge of each other they sought to use the 
information they had against each other. This was detrimental to the alliance but appears consistent with the external control of organizations theory. The theory sees organizations seeking to control their rivals.

Source: Authors Literature Review (2020)

\section{Methodology}

The study adopted a quantitative analysis that used a cross-sectional descriptive research design, with developed questionnaires structured to contain closed-ended questions using a 6point Likert-type scale measurement rating of Strongly Agree (6), Agree (5), Partially Agree (4), Partially Disagree (3), Disagree (2), and Strongly Disagree (1), intended to capture reality in quantitative terms. The population for the study was drawn from MSMEs operating within the Ojo Local Government Area (LGA) of Lagos State, Nigeria. Data obtained from NBS (2017) show that there are 8,395 registered MSMEs in Lagos State, representing $11.5 \%$ of the total number of MSMEs in Nigeria, a shape drop in the total of 11,663 registered SMEs, according to NBS (2016) data obtained by Adelekan, Eze, and Majekodunmi (2019). Registered MSMEs in the Ojo LGA were estimated to number 587, which serves as the population of the study. The sample for this research was drawn using the Taro Yamane (1963) sampling technique, which returned 234 MSMEs as the sample size. A total of 240 questionnaires were distributed to CEOs/managers of the MSMEs, of which 228 were returned valid and useable, constituting a $95 \%$ response rate, considered valid for the purpose of this study.

The reliability test was conducted using Cronbach's Alpha to ensure the internal consistency and stability of the measuring instruments; it returned a Cronbach's Alpha coefficient of 0.869 , as shown below (Table 2), which is acceptable reliability, and is an indication that the test result was consistent over time. Regression and correlation analyses were employed to analyse the data, while sample percentages and means were used for the demographic analysis of the respondents.

Table 2: Reliability statistics

\begin{tabular}{ll}
\hline Cronbach's Alpha & No of Items \\
\hline 0.869 & 10 \\
\hline
\end{tabular}

Source: Author's Computation 2020

\section{Data Analysis and Discussion of Findings}

Data was analysed using the respondents' returned questionnaires. A total of 228 questionnaires out of the 240 distributed, representing $95 \%$ of the sample size, were returned valid and useable. The research instrument was structured in a single section with 10 questions. The returned questionnaires were analysed using the Pearson Product Moment Correlation and Regression Analytical Tool on SPSS; the results obtained are as follows:

Hypothesis 1: $\mathrm{H}_{1}$ : Strategic alliance and partnership does not have an effect on MSMEs' survival post-COVID-19.

Table 3: Model summary 


\begin{tabular}{lllll}
\hline Model & R & R Square & Adjusted R Square & Std. Error of the Estimate \\
\hline 1 & $0.864^{\mathrm{a}}$ & 0.747 & 0.746 & 0.37707 \\
\hline
\end{tabular}

a. Predictors: (Constant), Strategic Alliance and Partnership

Table 4: ANOVA*

\begin{tabular}{lllcccc}
\hline Model & & Sum of Squares & df & $\begin{array}{c}\text { Mean } \\
\text { Square }\end{array}$ & F & Sig. \\
\hline & Regression & 104.054 & 1 & 104.054 & 731.849 & $0.000^{\mathrm{b}}$ \\
\hline 1 & Residual & 35.260 & 226 & 0.142 & \\
& Total & 139.314 & 227 & & \\
\hline
\end{tabular}

a. Dependent Variable: MSMEs Survival

b. Predictors: (Constant), Strategic Alliance and Partnership

Table 5: Coefficients ${ }^{a}$

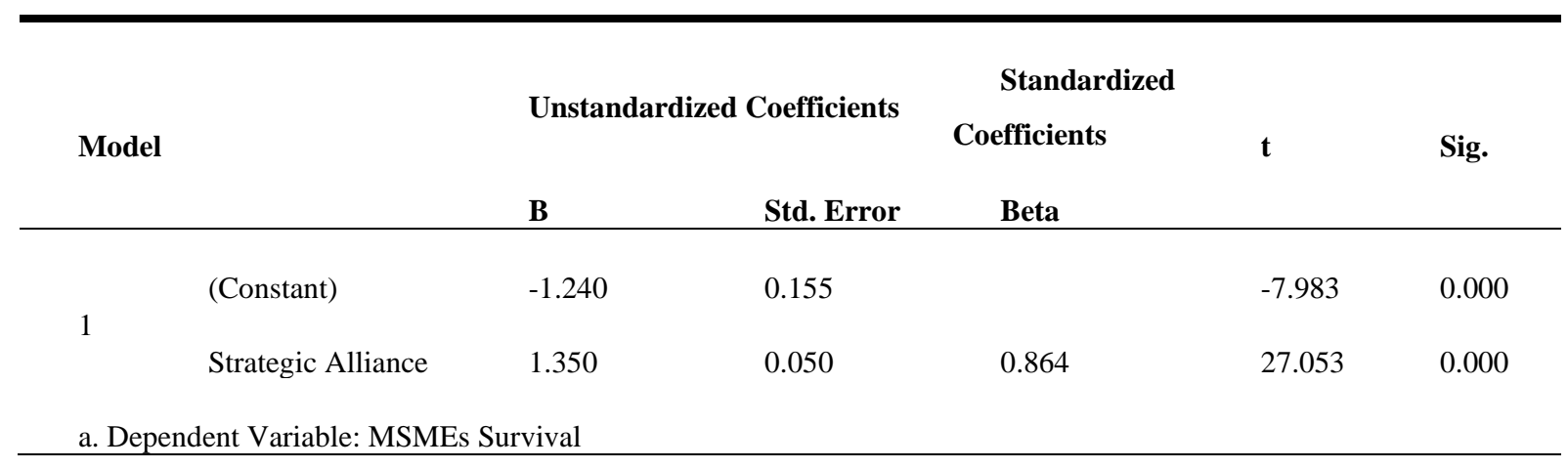

Source: Author's Computation 2020

The model summary table above (Table 3 ) shows the contribution of the predictor, Strategic Alliance and Partnership, to the dependent variable, MSMEs' Survival post-COVID-19. The $\mathrm{R}^{2}$ value of $0.747(74.7 \%)$ indicates the percentage of variation in the dependent variable, MSMEs' Survival post-COVID-19, which can be explained by the constant, Strategic Alliance and Partnership. The Anova table above (Table 4) shows the assessment of the regression model, which predicts the dependent variable's significance. This tests the null hypothesis to determine its statistical significance; the $\mathrm{F}$ value and $\mathrm{p}$-value are used to determine this. The result of the model in the table 4 above indicates that the regression model significantly predicts the outcome, since the p-value of $0.000<0.05$ and the $F_{\text {observed }} 731.849>F_{\text {critical }} 3.00$. The null hypothesis is therefore rejected, and we thus assert that strategic alliance and partnership positively affects MSMEs' survival post-COVID-19. The coefficient table above (Table 5) shows the contribution of the variables to the dependent variable. The study undertakes to compare the contribution of the independent variable, Strategic Alliance and Partnership, using the beta coefficient value of 1.350 in the unstandardised coefficient. This means that changes in the variable, Strategic Alliance and Partnership, will contribute positively to the survival of MSMEs post-COVID-19 in Nigeria. These findings are consistent with those of Tebrani's (2003). 
Hypothesis 2: $\mathrm{H}_{2}$ : Strategic Alliance and Partnership does not have any positive relationship on the performance of MSMEs post COVID -19 in the Nigerian economy.

The result of the correlation analysis (Table 6) for Hypothesis 2 tested above reveals that there is a perfect positive relationship between 'Strategic Alliance and Partnership' and the performance of MSMEs in the Nigerian economy post-COVID-19, as obtained by Pearson's correlation of 0.824 . The 2-tailed significance test result shows that $0.000<0.05$, which is the study's standard alpha value, and reveals that the study highly significantly predicts that 'Strategic Alliance and Partnership' will have a positive impact on the performance of MSMEs in the Nigerian economy post-COVID-19.

Table 6: Correlations

\begin{tabular}{llll}
\hline & & Strategic Alliance & Performance of MSMEs \\
\hline \multirow{2}{*}{ Strategic Alliance } & Pearson Correlation & 1 & $0.824^{* *}$ \\
& Sig. (2-tailed) & & 0.000 \\
& $\mathrm{~N}$ & 228 & 228 \\
& Pearson Correlation & $0.824^{* *}$ & 1 \\
Performance of MSMEs & Sig. (2-tailed) & 0.000 & \\
& $\mathrm{~N}$ & 228 & 228 \\
\hline
\end{tabular}

**. Correlation is significant at the 0.01 level (2-tailed).

Source: Author's Computation 2020

This finding is consistent with the findings of Akewushola et al. (2018) and Perry et al. (2004), who submitted that a strategic alliance was indeed a veritable tool in enhancing organisational performance.

\section{Conclusion and Recommendations}

It is obvious that these are not favourable times for organisations, businesses, managements of business, and all stakeholders involved in the business environment globally. MSMEs are the most adversely affected across the globe, with billions of dollars lost daily to the ongoing pandemic and millions of jobs lost across every sector of the world's economies; even MSMEs in developed industrial countries are all seeking ways to survive and continue operations, with profit maximisation now a secondary objective for business. Most MSMEs in the world's developed economies are seeking government interventions, with their governments responding by providing interest-free loans to boost their various economies, and agreeing to furlough staff to pass their salaries onto ailing businesses. The case with MSMEs in Nigeria (a developing country) is different, with all MSMEs finding it difficult to sustain their operations, with no support from the government or the financial houses that are supposed to be the lenders of credit and providers of loan facilities (who themselves are struggling to survive the impact of the COVID-19 pandemic on their businesses, with reports of some commercial banks laying off staff).

The best option for firms, especially MSMEs in Nigeria and other developing countries, is to enter into strategic alliances with other firms, which would allow each firm total retention of 
their identity and help bolster the strength and resources needed for survival and continued operations post-COVID-19. It is therefore recommended that MSMEs seek strategic alliance partners not necessarily in the same line of business; thus, firms involved can retain their identity, survive, and still perform optimally.

Author contributions: All authors listed have made a substantial, direct and intellectual contribution to the work, and approved it for publication.

Funding: This paper is an output of a social science study conducted to find solution to challenges faced by MSMEs in the light of the COVID-19 Pandemic that has affected humanity and business operations and survival. It must be noted that the authors did not receive any financial grant or sponsorship from any organization or body. All financial needs associated to this study were borne by the authors.

Data Availability Statement: Data available on request.

Conflicts of Interest: The authors declare no conflict of interest

\section{References}

Adelekan, S. A., Eze, B. U., \& Majekodunmi S. A., (2019). Bank Loans and Small Medium Enterprises' (SMES) Performance in Lagos, Nigeria. Ilorin Journal of Human Resource Management (IJHRM), 3(1), 52-61.

Akanbi, P.A., Ayodele, T.D., \& Adedipe, O.A. (2014). An investigation in some factors influencing the intention to use internet banking among undergraduates in Nigeria. Research of Finance and Accounting, 5(8), 1-10.

Akewushola, R. O., Tijani, A. A., \& Adelekan, S. A., (2018). Strategic alliance and firm performance: A focus on service industry. Crawford Journal of Business \& Social Sciences (CJBASS), 8(2), 84-91.

Aminu, I. M., \& Shariff, M. N. M. (2015a). Determinants of SMEs performance in Nigeria: A pilot study. Mediterranean Journal of Social Sciences, 6(1), 156.

Anand, B. N., \& Khanna, T. (2000). The structure of licensing contracts. Journal of Industrial Economics, 48, 103-135.

Arndt, M. (2009). Cisco's failure in corporate alliances. Accessed in Matata, M. \& Petronilla, O. (2014). Effects of strategic alliances on organizational performance: Supermarkets and their alliances in Kenya. European Journal of Business and Management, 6(34), 75-89.

Ayandibu, A. O., \& Houghton, J. (2017). The role of small and medium scale enterprise in local economic development (LED). Journal of Business and Retail Management Research, 11(2).

Bremen, P., Oehmen, J., Alard, R., \& Sconsleben, P., (2010). Transaction costs in global supply chains of manufacturing companies. Journal of Systemics, Cybernetics \& Informatics, 8, 19-25.

Camisón, C., Boronat, M., \& Villar, A. (2007). Technical strategic alliances and performances: The mediating effect of knowledge-based competencies. Universitat Jaume, 5(4), 586- 593.

Colombo, M. G. (2003). Alliance form: A test of the contractual and competence perspectives. Strategic Management Journal, 24, 1209-1229.

Ekpudu, J. E., Aigbepue, S., \& Olabisi, J. O. (2012). Appraisal of strategic alliances and corporate effectiveness. International Multidisciplinary Journal, 7(1), 155-164.

El-Erian, M. (2020). The coming coronavirus recession and the uncharted territory beyond. Foreign affairs, media report. Available at: https://www.foreignaffairs.com/articles/2020-03- 17/coming-coronavirus-recession.

Eze, B. U., \& Cesar, C. (2021). COVID-19: An assessment of MSMEs survival strategies in Nigeria and Peru. Hallmark University Journal of Management and Social Sciences (HUJMSS), 3(1), 123-129.

Eze, B. U., Oladimeji, M. S., \& Fayose, J. (2019). Entrepreneurial orientation and micro, small and medium enterprises (MSMEs) performance in Abia State, Nigeria. Covenant Journal of Entrepreneurship, 3(1), 19-35.

Ibrahim, M. (2011). Strategic alliances in international marketing. Accessed in Matata, M. \& Petronilla, O. (2014). Effects of strategic alliances on organizational performance: supermarkets and their alliances in Kenya. European Journal of Business and Management, 6(34), 75-89. 
Ifekwem, N., \& Adedamola, O. (2016). Survival strategies and sustainability of small and medium enterprises in the oshodi-isolo local government area of Lagos State. Acta Univ. Sapientiae, Economics and Business, 4, 103118.

Jabar, J., Othman, A., \& Idris, M. (2011). Enhancing organizational performance through strategic technology alliances: A study on Malaysian manufacturers. International Journal of Innovation, Management and Technology, 2(6), 506-511.

Khanna, T., Gulati, R., \& Nohria, N. (2000). The economic modeling of strategy process: 'Clean models' and 'dirty hands.' Strategic Management Journal, 21(7), 781-790.

Mohamed, Z. (2014). Strategic alliance slideshare presented to Dr. Amr Kheir El din ESLSCA global business diploma October 2014. Available at https://www.slideshare.net/mohamedzmohamed2/strategic-alliance40663452 Accessed on 27th July, 2020.

Mohammad, W. H., Ashikul, H., Farzana, A. S., Mashrekha, A., Abu-Bakar, A. H., \& Huam, H. T., (2020). The impact of coronavirus (COVID-19) on E-Business in Malaysia. Asian Journal of Multidisciplinary Studies, $3(1), 1-7$.

Musah, A. (2017). Benefits and challenges of bookkeeping and accounting practices of SMEs and its effect on growth and performance in Ghana. JABM Journal of Accounting-Business \& Management, 24(2), 16-36.

Nooteboom, B. (2004). Governance and competence: How can they be combined? Cambridge Journal of Economics.

Oke, M. O., \& Aluko, O. A. (2015). Impact of commercial banks on small and medium enterprises financing in Nigeria. IOSR Journal of Business and Management, 17(4), 23-26.

Ozili, P. K, \& Arun, A. (2020). Spillover of COVID-19: Impact on the global economy. Available at SSRN Electronic Journal, March 2020, https://www.researchgate.net/publication/340236487

Perry, M., Sengupta. S., \& Krapfel, R. (2004). Effectiveness of horizontal strategic alliances in technologically uncertain environments, are trust and commitment enough? Journal of Business Research, 57(9), 951-956.

Ribeiro-Soriano, D. (2017). Small business and entrepreneurship: Their role in economic and social development: Routledge.

Sipahi, E. (2020). COVID-19 and MSMEs: A revival framework. Research Journal in Advanced Humanities, 1(2), 7-21.

Tebrani, M. (2003). Competitive strategies, strategic alliances, and performance in international high-tech industries, a cross-cultural study. Journal of American Academy of Business, 2 (2), 610-617.

Williamson, O. (1979). Transaction-cost economics: The governance of contractual relations. Journal of Law and Economics, 22, 233-261.

Williamson, O. (1986). Transaction-cost economics: The governance of contractual relations. In J. Barney \& W. Ouchi (Eds.), Organizational economics (pp. 98-129). San Francisco: Jossey-Bass.

Williamson, O. E. (1999). Strategy research: Governance and competence perspectives. Strategic Management Journal, 20(12), 1087-1108.

World Health Organization (2020). Pneumonia of unknown cause-China. Retrieved from https://www.who.int/emergencies/diseases/novel-coronavirus-2019/situation-reports. $11^{\text {th }}$ day of July, 2020 